\title{
UMA REALIDADE INVISÍVEL: violência contra alunas negras na escola pela percepção dos docentes
}

\author{
Ligia Costa Leite \\ Rosse Imair de Oliveira Melo \\ Cristina Maria Donat Donat
}

\section{Resumo}

O presente artigo pretende investigar, por meio de entrevistas realizadas com professores do Instituto Federal de Educação, Ciências e Tecnologia do Maranhão (IFMA), Campus Buriticupu, no Nordeste do Brasil, a invisibilidade da violência racial e de gênero enfrentada por alunas negras. A abordagem qualitativa e a análise temática são os instrumentos utilizados para a coleta e a interpretação dos dados das entrevistas. Para analisar as dificuldades dos docentes em lidar com essas situações, o artigo divide-se em três temas ou unidades de significação, relacionados com educação e saúde: etnia e cultura, violências de gênero e procedimentos institucionais. Os resultados apontam como a violência se oculta em uma forma silenciosa que se sobrepõe às demais e acaba negligenciada, naturalizada ou banalizada por quem a perpetra, por quem a assiste e por quem a sofre.

Palavras-chave: escola; violência silenciosa; alunas negras; racismo estrutural.

\section{AN INVISIBLE REALITY: violence Against Black Schoolgirls Through the Perception of Their Teachers}

\begin{abstract}
This article seeks to investigate, through interviews carried out with teachers from the Federal Institute of Education, Science and Technology of Maranhão (IFMA) at Buriticupu, in Northeastern Brazil, the invisibility faced by black schoolgirls due to racial and gender violence. The qualitative approach and thematic analysis are the tools used for collecting and interpreting interview data. To analyze the difficulties of schoolteachers in dealing with these situations, the article is divided into three themes or units of meaning regarding education and health issues: ethnicity and culture, gender violence, and institutional procedures. Results show how violence is hidden in a silent way and overlaps with other types of violence, which is then neglected, naturalized, or trivialized by perpetrators and victims, as well as by those watching from outside. Keywords: school; silent violence; black schoolgirls; structural racism.

UNA REALIDAD INVISIBLE: violencia contra escolares negras según la percepción de los profesores
\end{abstract}

Resumen

El presente artículo investiga, a través de entrevistas con docentes del Instituto Federal de Educación, Ciencia y Tecnología de Maranhão (IFMA), en Buriticupu, en el Noreste de Brasil, la invisibilidad de la violencia racial y de género que enfrentan las escolares negras. El enfoque cualitativo y el análisis temático son las herramientas que se utilizan para recopilar y interpretar los datos de las entrevistas. Para analizar las dificultades de los docentes para afrontar estas situaciones, el artículo se divide en tres temas o unidades de significado relacionados con la educación y la salud: la etnia y la cultura, violencia de género y procedimientos institucionales. Los resultados muestran cómo la violencia se esconde de forma silenciosa que se solapa con otras y acaba siendo descuidada, naturalizada o banalizada por quienes la perpetran, por quienes la miran y por quienes la sufren.

Palabras clave: escuela; violencia silenciosa; escolares negras; racismo estructural. 


\section{CONSIDERAÇÕES INICIAIS}

Neste artigo pretende-se articular os conceitos teóricos de violência, preconceitos étnicos, de gênero e machismo de uma sociedade historicamente patriarcal, com o objetivo de melhor conhecer a realidade de alunas negras que estudam em uma escola em Buriticupu, no interior do Estado do Maranhão, a partir de entrevistas com docentes em suas percepções sobre essas vivências.

Violências são episódios multifacetados e multicausais, capazes de alterar a percepção individual, o bem-estar emocional e a saúde mental daqueles que as sofrem e com frequência daqueles que as praticam. Elas são capazes de reduzir a habilidade de cada um para funcionar de forma independente e autônoma no seio da sociedade. Parte-se, aqui, da definição utilizada pela Organização Mundial da Saúde:

[...] uso intencional da força física ou do poder real ou em ameaça, contra si próprio, contra outra pessoa, um grupo ou uma comunidade, que resulte ou tenha qualquer possibilidade de resultar em lesão, morte, dano psicológico, deficiência de desenvolvimento ou privação. (OMS, 2002, p. 5).

Geralmente, os tipos de violência surgem em relações desiguais de dominação pela brutalidade, força, coação ou constrangimento. Dentre suas formas, a física é a mais explícita, pois deixa marcas corporais visíveis. Entretanto, não se pode restringir a violência apenas àquelas conhecidas, uma vez que ela é parte intrínseca da natureza humana e, assim como o sofrimento, está presente em diversos momentos da vida social.

Outro conceito de violência é a silenciosa, expressa em atos: "sutilmente escamoteados e camuflados e, talvez, muito mais violenta do que sua forma aparente, pois se expressa pela [...] falta de direitos básicos, como trabalho, educação, saúde, justiça, entre outros" (AUTOR, ano, p.X), sendo aceita naturalmente. Isso se observa em todos os grupos sociais quando a dignidade humana é violada por discriminações e preconceitos, por práticas institucionais e, particularmente, por inércia de gestores das políticas públicas que não cumprem as leis e a Constituição. Na maior parte das vezes, apresenta-se em atitudes cotidianas, em comportamentos e omissões diversos, sem que os sujeitos compreendam claramente as inúmeras imposições a que são submetidos. Os danos que lhes são causados, nem sempre são objetivos e que podem originar sofrimento psíquico, levando o indivíduo a negar o acontecido e até mesmo a se recusar a pensar ou falar sobre ele. Por ser dissimulada, é impossível de ser quantificada através de instrumentos específicos, não sendo partes das estatísticas oficiais.

Essa configuração está presente historicamente do Brasil em um aspecto que se reproduz continuamente: o preconceito etnicorracial e de gênero, que afeta e segrega mulheres negras. A rejeição está presente em todos os espaços do país porque, além da não aceitação de diferenças culturais, o racismo estrutural propaga a ideia do "outro inferior". De acordo com Sodré (2015), as crenças da inferioridade dos afrodescendentes são produzidas desde a escravidão e aparecem na segregação étnica persistente, gerando mal-estar e baixa autoestima em jovens negras. Assim, podese afirmar que a democracia racial que supostamente vive-se no Brasil é um mito, com amarras invisíveis e violências silenciosas que servem para negar ou suavizar a existência do segregacionismo. Isso revela o DNA simbólico da sociedade e esvazia qualquer discussão séria sobre o tema (SOUZA, 2017).

Outro mito brasileiro é o da inferioridade da mulher e da negra ainda mais, presente na atualidade em várias esferas sociais e diferentes faixas etárias, sobretudo na cultura familiar nordestina que é machista e um agravante para violência. Nessa região os homens consideram ter o domínio primário na liderança doméstica, política, na autoridade moral, com o privilégio do 
controle total dos bens conjuntos, com a posse do cônjuge e pai, para educar suas esposas ou filhas com castigos físicos e violências (FÉRES-CARNEIRO, (2013). Mesmo com diversos estudos sobre o racismo/machismo no Brasil, como no Dossiê de Mulheres Negras no Brasil (IPEA, 2013), as evidências sobre esse tema são bem mais silenciadas e, portanto, têm maior dificuldade em serem reveladas, como se observa no Maranhão.

Nesse aspecto, para existir uma conduta ideal de docentes dentro dos princípios específicos do contexto sociocultural das alunas negras, que é o foco desse estudo, deve haver ações que determinem "o campo de comunicações possíveis, dos valores ou das ideias presentes nas visões compartilhadas pelos grupos que regem, subsequentemente, as condutas desejáveis ou admitidas". (MOSCOVICI, 1978, p. 51). Ou seja, pretende-se observar condutas e atitudes sobre racismo e discriminação de gênero, que refletem comportamentos dentro dos valores específicos de cada cenário e se referenciam em representações sociais (RS). Estas fornecem "uma forma de conhecimento, socialmente elaborado e compartilhado, com um objetivo prático, e que contribui para a construção de uma realidade comum a um conjunto social" (JODELET, 2001, p. 22). Isso não é diferente na escola brasileira que ignora a singularidade das alunas negras não lhes dando vOz, nem reconhecendo as agressões que sofrem, de modo que elas acabam vitimadas, notadamente entre as classes mais pobres das zonas rurais e municípios do Nordeste.

Com o objetivo de conhecer melhor essa realidade, a partir das narrativas de docentes, busca-se investigar a percepção deles a respeito das violências vividas por meninas negras, dentro e fora do lar. Essas considerações introdutórias apresentam-se nas falas de um grupo de educadores da escola pesquisada.

O estudo foi aprovado pelo Comitê de Ética e Pesquisa da Universidade CEUMA, conforme resolução 466/2012, e registrado com o número CAAE 86056317.7.0000.5084.

\section{APORTE TEÓRICO-METODOLÓGICO}

Com um enfoque qualitativo, usando a ferramenta da análise temática (BRAUN; CLARK, 2013), explora-se as percepções dos professores sobre uma realidade nem sempre visível, para extrair significados, opiniões, valores e atitudes a respeito de fatos e cenários que podem elucidar situações de violências omitidas e/ou consideradas irrelevantes dentro da sala de aula. Assim, delineia-se categorias-tema que informam como se organizam significados evocados pelos sujeitos sobre o tema, para desvelar a estrutura das RS referenciadas por eles. Os núcleos de sentidos e modelos de comportamento dos docentes, presentes nas entrevistas, apresentam alguma frequência em determinados assuntos e elaboram, nas respostas dadas, explicações nem sempre objetivas. Esses núcleos permitem extrair pontos subjetivos, revelar motivos/causas e, com isso, evidenciar elementos das RS inerentes aos modos de pensar e agir, de atos e circunstâncias implícitas. que ocultam acepções denunciadoras de preconceitos, ainda que nem sempre são observadas claramente por eles.

O local do estudo é o Instituto Federal de Educação, Ciências e Tecnologia do Maranhão (IFMA), Campus Buriticupu, que oferece treze cursos de formação de nível médio, profissionalizante, superior e de educação de jovens e adultos, além de alguns programas especiais do Ministério da Educação. Segundo o Censo Escolar 2017 (INEP, 2017), a Escola tinha, então, 1.428 matriculas, sendo 564 do gênero masculino e 864 do feminino. O local dispõe do NAE (Núcleo de Assistência ao Educando) que realiza atendimentos individuais com uma equipe interdisciplinar de pedagogia, psicologia, assistência social, medicina e enfermagem.

Para escolha da população entrevistada, adota-se uma estratégia de amostragem qualitativa conveniente (MILES; HUBERMAN, 2019), que pressupõe o reunir sujeitos de um grupo 
predefinido. O número total de docentes em sala de aula naquele ano na escola era 113 e vinte e dois aceitaram participar do estudo, não estando de licença ou afastados do trabalho. Em um enfoque qualitativo, esse número poderia ser menor em função da chamada saturação dos dados, ou seja, quando o pesquisador atinge a compreensão da lógica das respostas que se repetem sem trazer novos aspectos. Portanto, os entrevistados desse grupo trazem a representatividade do total dos docentes (MINAYO, 2017).

Um roteiro básico semiestruturado para guiar as entrevistas foi estruturado, com questões reformuláveis sempre que fosse necessário aprofundar algum aspecto não muito claro, sem perder o foco do estudo. Com esse material pode-se captar juízos de valor e RS que emergiram das descrições feitas nas relações com as alunas. As entrevistas foram gravadas no período de agosto a outubro de 2019.

Por fim, os dados foram examinados dentro da perspectiva reflexiva da análise temática, para encontrar elementos do núcleo das RS, que articulassem as entrevistas com os objetivos propostos. E as categorias-temas definidas de acordo com as etapas de pré-análise; exploração dos dados; tratamento/interpretação dos resultados.

\section{RESULTADOS E DISCUSSÃO}

Seguindo Braun e Clark (2013), do material coletado, selecionou-se os padrões que tivessem pertinência ao objeto estudado, anotados de forma livre, fluida e flexível em caderno de campo, tais como questões e observações resultantes. Essas informações podiam ser modificadas e/ou confirmadas, constituindo um processo estruturado para oferecer resultados fidedignos à matéria por meio da conceitualização, junção ou separação dos conteúdos para definição das categoriastemas a serem criadas.

Dos 22 docentes entrevistados, quatorze eram do gênero masculino, com idades entre 30 e 40 anos e oito do feminino, com idades entre 20 e 45 anos. Todos eram do quadro de servidor público federal, com dedicação exclusiva (40 hs).

Imergindo profundamente nos dados, pela voz desses, e articulando-os com a questão estudada, percebeu-se e refletiu-se sobre a falta de visibilidade com relação às violências sofridas por alunas negras no contexto intra e extraescolar. Os temas para análise foram: etnia e cultura; violências de gênero; procedimentos institucionais.

\section{Etnia e cultura}

A diversidade sociocultural entre alunos e funcionários é acentuada e nem sempre há comunicação entre esses dois lados, o que demonstra não haver consciência dessa disparidade. Os gestores escolares, por sua vez, não propõem ações para um encontro de culturas/realidades, assim como não há discussão sobre desigualdades, costumes e práticas que explicitem alguns traços peculiares, como as violências contra alunas negras.

A escola, em sua função primária, deve visar à transformação e ao desenvolvimento saudável do aluno no convívio diário para sua interação social, sendo um local significativo e privilegiado para distinguir/atuar em uma realidade de maus-tratos que as discentes enfrentam. Deste modo, o objetivo, aqui, é utilizar esse material como instrumento de uma discussão ampla sobre educação e saúde, que supere o silêncio diante de agressões diversas e crie um novo olhar para impulsionar o enfrentamento das violências vivenciadas, como propõe Jesus e Monteiro (2016).

A pesquisa de Almeida et al (2018) mostra que esses tópicos nem sempre são enfrentados, mas silenciados, uma vez que não existem protocolos de registro, encaminhamento e proteção. $\mathrm{O}$ 
assédio sexual e outras formas de agressão aparecem relatados nas entrevistas, porém de modo geral porque o IFMA não tem projetos para tratar das questões etnicorraciais observadas, nem interagir com a comunidade sobre o tema na qual as alunas estão inseridas:

Eu já participei de eventos com relação à violência contra mulher no geral, no projeto "Xô assédio", em que elas declaravam assédio [...] que já sofreram no dia a dia, na rua, em casa etc. Participei também de trabalhos que eram feitos na disciplina de Combate à Violência, inclusive com sensibilização dos alunos com relação à denúncia e a qualquer outro fato que poderia estar relacionado com esse assunto. Mas não havia nada relacionado diretamente a questões raciais. (VI) ${ }^{1}$

No NEABI (Núcleo de Estudos Afro-brasileiro e Indígena), existem algumas ações para integração étnica, porém nenhuma específica sobre abuso contra alunas. Além disso, as atividades são esporádicas e ficam concentradas naquele local, não tendo o envolvimento da gestão escolar, conforme descrito abaixo:

[Ali] a gente faz a discussão de textos relacionados às práticas dos afrodescendentes ou indígenas, [...] em momentos que tá acontecendo alguma coisa e a gente precisa falar disso, porque são adolescentes, então tudo que eles veem na rede social é discutido, tipo grupo de discussão, para eles apresentarem suas ideias, o que eles veem, o que pensam. [...] e aí que os meninos falaram dos índices de violência contra mulher negra. (IX)

Outro ponto de destaque quanto ao contexto étnico-cultural dentro da escola é apontado por uma professora, que alega existir um número grande de homens (docentes e servidores) que naturalizam comportamentos machistas e que não conseguem enxergar violências para além das agressões físicas. Assim, ela enfatiza a importância de discussões em equipe e com a família, sobre etnia, gênero, orientação sexual e outras violências silenciosas vividas pelas alunas:

Todo e qualquer projeto que discuta os direitos das minorias é favorável, ainda mais quando saia da instituição e atinja a comunidade. Um projeto que trate da violência contra a mulher principalmente $[\ldots]$ porque ainda é um dado muito velado, muitas [alunas] não querem denunciar, mas é importante para diminuir o feminicídio desde muito cedo. Qualquer evento é pouco para discutir essa situação. (VIII)

Durante a entrevista, uma docente percebe que suas dificuldades diante da violência contra alunas negras são decorrentes de suas intolerâncias, como aponta abaixo:

A gente tem vergonha dos nossos próprios preconceitos, não quer assumir que faz essa diferenciação, é uma autoanálise o tempo todo. [...] a gente tem tanto preconceito dentro de uma comunidade, dentro da escola, dentro da sociedade [...] são tantos casos, fora o da mulher negra, [...] como também do homem negro homossexual. Então [...] é difícil reconhecer que na sociedade atual, com tudo que a gente sabe, que você precisa estar lutando o tempo todo com essa questão da violência, de se achar superior a outro, da questão de raça. É muito difícil de encarar isso. (IV)

Outra enfatiza para a necessidade de procurar superar coletivamente a questão por meio da educação, pois essa atinge tanto o agressor quanto a agredida:

1 Os números romanos ao final de cada citação são referentes aos entrevistados, visando a assegurar o sigilo dos dados e a privacidade dos participantes. 
Dá pra a gente tentar desconstruir algumas coisas em relação ao preconceito? [...] é um tema relevante. É super atual também. Porque já foi tanto tempo silenciado, especialmente na escola $[\ldots]$ a violência ainda está muito presente. $[\ldots]$ independe de gênero, masculino e feminino. É muito grave essa questão, como também do preconceito racial como um todo. A vítima é a mulher, mas o agressor é do sexo masculino, então seria uma questão de conscientização mesmo. De educar e conscientizar sobre a temática. (I)

Violência contra mulheres negras tem sido uma situação complexa, histórica e não facilmente assimilada como abuso, até porque as RS que lhes servem de referência costumam aceitar e naturalizar esses atos. Mesmo em um momento em que ocorre maior divulgação na mídia, há poucas acusações:

A gente pode criar várias hipóteses: teoricamente a mulher branca tem mais instrução e sabe buscar mais seus direitos, enquanto a negra teria baixa instrução, na média, e não saberia onde buscar os seus direitos e como se proteger. A gente também pode chegar à hipótese de que não há um aumento da violência, há um aumento de denúncias, com mais informação, mais casos registrados, então existem várias variáveis para responder isso aí. Se a gente fizesse um estudo por região, a violência no Nordeste com certeza é maior que no Sul. (III)

Para admitir a gravidade desse assunto, bem como verificar e prevenir possíveis feminicídios, é preciso haver debates na escola, de modo a romper a barreira do silêncio e colocar a aluna como vítima que sofre agressões. Muitas vezes nesse ciclo contínuo em que os abusos são constantes, pode vir a ser comum a ocorrência do homicídio feminino (MENEGHEL et al, 2017). É urgente criar protocolos, articulando educação e saúde, para notificar e acolher os casos, agindo com cautela, sem impor decisões, sem pressionar e sem julgar, de forma hábil e resolutiva para proteção da jovem, rompendo constrangimentos e opressões de modo mais efetivo, como expresso abaixo:

[...] primeiro, esclarecer o que é violência, incluindo a doméstica, com diversos profissionais das áreas da saúde, jurídica, da assistência social. Uma palestra geral, depois, um grupo de trabalho, debatendo o tema com vídeos impactantes. Em seguida, juntar ministério público, defensoria, órgãos do Poder Judiciário e escola para montar um plano de ação com prazos, metas e orçamento. Um planejamento mesmo com uma equipe de monitoramento, indo às comunidades, e as comunidades vindo até a escola, fiscalizando. (XXII)

Cultura e etnia, portanto, são questões fundamentais a serem discutidas no espaço escolar, para trazer à luz segregações existentes na sociedade, criando, ao mesmo tempo, uma rede eficaz e transversal, para protocolar e reconhecer os riscos aos quais as jovens agredidas estão expostas.

\section{Violências de gênero}

Como já descrito acima, violência e dominação masculina, silenciosas ou não, presentes no cotidiano das alunas negras, podem gerar riscos e fragilidade, bem como causar constrangimento naquelas que sofrem essas agressões por parte de um conhecido, familiar ou dentro da escola ao ser alvo de bullying. A cultura machista faz parte da constituição da identidade social é um elemento forte nas RS, permitindo subjetivamente que professores/as não atentem para esses atos intra ou extrafamiliar das alunas. Pode-se destacar que socialmente a mulher negra ainda é a maior vítima e 
sofre com a posição submissa que ocupa historicamente, tornando-a invisível e a mercê da visão dos homens (OLIVEIRA et al, 2018).

Portanto, um aspecto importante que surge neste estudo é o contexto familiar das alunas e a impotência delas diante da violência. A cultura maranhense, e de todo Nordeste, vem perpetuando agressões domésticas sem que as mulheres resistam a isso. Como reflete uma docente, esse comportamento machista aparece na própria forma de educar os filhos, reproduzindo essa cultura: "A gente manda a menina lavar a louça e o menino fazer outra atividade ou, então, nem manda nada" (IV).

Condutas violentas dos pais são fruto de relações ali existentes e costumam ser reproduzidas pelos filhos, pois naquela família a agressão é considerada a forma predominante de resolução de conflitos (COSTA; TEIXEIRA, 2017). Assim, alunos/as reproduzem e naturalizam a violência recebida na formação familiar e têm uma tendência em silenciá-la. São frequentes os casos de discentes que cometem bullying na escola porque são vítimas de violência em casa (MELLO et al, 2017). Por isso, alunas que sofrem essas brutalidades ou já as presenciaram anteriormente, do pai contra a mãe, aceitam o mesmo comportamento abusivo após se casarem — geralmente muito cedo - , pois aquilo é considerado "normal" e "admissível":

A gente tem um receio de ser confrontado com a agressão doméstica, porque na realidade é o "normal". Esse é o problema! Às vezes pode parecer anormal para a gente e é normal na vida daquela pessoa. Aí é o tal do choque cultural, essa é a casa que as pessoas moram, os meninos são criados na pancada para ser homem. A gente acha um comportamento anormal, denuncia e constata que até para as filhas é normal: "Ele só me deu um soco na cara, não fez nada mais do que isso". (XI)

Razera e Falcke (2014) pontuam que alguns casais não entendem a atitude agressiva como algo violento e prejudicial, portanto, não veem a necessidade de separação. Além disso, continuidade da relação conjugal também é influenciada por outros fatores, como a dependência financeira, a dificuldade na criação dos filhos e até mesmo o medo de ficar sozinha. Esse entendimento sobre a violência explícita contra a mulher é comentado em duas entrevistas. A primeira ratifica a subjugação feminina pela cor da pele e a outra no incomodo pela descrição explícita das alunas em aula:

Pelo fato do parceiro ser de outra etnia, por ele ser branco, acredito que fica mais visível esse sentimento de superioridade em relação à esposa negra, assalariada. Dele ter um poder aquisitivo maior e ela não ter um grau de instrução tão elevado por causa de tantas desigualdades, fica mais escancarado ainda, a probabilidade da violência é maior. (VII)

Eu fui assistir uma atividade na Educação de Jovens e Adultos, que eles criavam o texto e iam lendo, eita, foi pesado. O que tinha de mulher agredida pelo marido, pelo pai, pela mãe, pelo irmão. E estuprada, ah!!! Teve demais [...] Foi estuprada pelo irmão, pelo padrasto. Mataram o pai na frente dela, um que foi abandonado no lixo, teve de tudo, todo mundo tinha uma história absurda para contar. (XII)

Um professor, ao ver o sentimento de tristeza de uma jovem, dispersa em sala de aula e sem iniciativa para confrontar o vivido, comenta sobre a necessidade de um auxílio mais direto a esses episódios:

Para que a pessoa tome uma posição, não basta só mostrar a dor. Eu acredito que tem que se mostrar como resolver o problema [...]. Vamos ver como é, é se 
separando do agressor? Sim. Então vamos ver como é feita essa separação. A questão dos filhos, o atendimento. Vamos lá, eu levo você e tal. A gente tem que dar força para que ela consiga se recuperar. [...] se estamos lá in loco, se somos professores da aluna, precisamos ter o comprometimento de tentar dirimir esses conflitos e se a gente não consegue, passa para as outras instâncias, sempre pedindo orientação dos profissionais da casa de uma forma sutil. (XX)

Algumas jovens não aceitam interferência da escola, de professores ou outras pessoas em aspectos de sua vida privada, mesmo quando a situação é percebida, mas, por vários motivos, elas decidem permanecer com o agressor, o que surpreende uma entrevistada: "[...] tem aquelas mulheres, no caso da aluna que dependia do marido, que não querem ser ajudadas, ela volta para ele o tempo inteiro" (X).

Há casos concretos, presentes em mais de uma entrevista, em que as vítimas têm receio em fazer a denúncia, pois não acreditam na rede de proteção, uma vez que já vivenciaram fragilidade e o desrespeito dos profissionais desses locais, que invertem o papel da posição de agredida para a de culpada. Isso, junto com a lentidão do sistema jurídico, da sociedade e dos órgãos supostamente protetivos, produz o descrédito à denúncia, como narrado por uma docente: “[...] a aluna ao tentar interromper o ciclo de violência psíquica vivida em casa e não consegue denunciar o pai, pois o delegado [possivelmente machista] não quis registrar a queixa por não haver sinais físicos". (XII).

Além disso, os programas sociogovernamentais são poucos conhecidos e não dão o amparo necessário: "Eu acho que nós deveríamos criar um canal virtual de apoio" (XIX), sugere outra professora.

Por outro ponto de vista, há divergências entre os entrevistados no entendimento sobre abusos físicos ocasionados pelos responsáveis. Um docente supõe que, apesar de não concordar com agressão em que haja espancamento - dependendo de quem o faz e do local onde é atingido — os "responsáveis têm o direito de corrigir e educar os filhos" (XIV). Ele diferencia agressão de correção, mesmo ambas sendo físicas e implicando em equimose:

Existe a agressão e a correção, a agressão para deixar marca se torna física, se torna abusiva, a gente percebe as marcas físicas ou psicológicas, a gente percebe quando não é correção. Quando, por exemplo, o pai bate porque ele está bêbado, não é correção, o irmão chega drogado e bate na irmã, isso não é correção. [...] quando a aluna vem chorando, não consegue falar e fica tentando achar rodeios para falar, a gente percebe que foi agressão de outro tipo. (XIV)

Para os docentes do gênero masculino, silenciar a dor é comum entre as alunas, apesar da visibilidade das violências do namorado, irmão, pai ou outros. Quando uma equimose é notada, ela explica que foi um acidente, o que cala, talvez confortavelmente, quem fez a pergunta, ainda que permaneça a dúvida com lesões aparentes, como entende um entrevistado:

Primeiro porque é fala de mulher, aí o machismo não deixa, e segundo porque é fala de negra que também foi colocada há muito tempo à margem. Então quando junta mulher e negra, é invisível! Ninguém precisa saber, a sociedade faz isso, nós fazemos isso? Mas nós somos a sociedade. (XVII)

Elas negam esses fatos, talvez, por vergonha, como explica: "Eu sou um homem e as alunas não sentem muito à vontade para falar sobre isso com alguns homens. Por isso a importância do debate mais profundado sobre como lidar com o tema" (XXI).

Conflitos sociais interferem na vida escolar e extraescolar das alunas, vulnerabilizando-as. As condutas de segregação e desrespeito produzem desconforto. Para Silva e Ferreira (2014), 
práticas como intolerância, violência, bullying, entre outras, são desumanas e violam o direito de liberdade e de livre expressão, como corrobora a entrevistada abaixo:

[...] já aconteceu várias vezes comigo, de perceber. Por exemplo, a aluna $\mathrm{M}$ que normalmente é muita extrovertida e de repente tá muito calada e eu tento puxar um assunto sem sucesso [...]. A gente sempre pensa que tem alguma coisa em casa [...] ou que tá sofrendo bullying na escola ou tem algum aluno da escola que está insuportavelmente dando em cima dela e ela não aguenta mais ou tem algum professor que está assediando-a e ela não aguenta mais [...]. (V)

Uma postura recorrente de vários professores, ao verificar abusos, é defender o anonimato e agir informalmente, justificando que estão protegendo as jovens e evitando a propagação do evento por toda a escola. No entanto, notificar esses atos aos superiores é uma medida compulsória, além de envolver a ética profissional, que precisa ser seguida. A humanização na abordagem e a atenção qualitativamente diferenciada na convivência em sala de aula, além de possibilitar maior vínculo com a aluna, ajuda a tornar consciente a violência e buscar interromper esse ciclo. (DAVID et al, 2015). O segredo é um agravante, pois fortalece situações superpostas, o que dificulta a identificação e o enfrentamento das agressões. Afinal, não dar conhecimento ao fato ou não discutilo proporciona uma "invisibilidade" que estimula atos hostis e preconceituosos, levando-os a se perpetuarem sem consequências para o agressor (MADUREIRA; BRANCO, 2015).

Outra menção nas entrevistas são as chantagens emocionais dos familiares com ameaças verbais de castigar as filhas que tiram notas baixas. Uma professora admite que é comum ouvir relatos sobre isso e que ela só observou essa atitude como violência silenciosa após esta entrevista, quando passou a avaliar que essas posturas domésticas exigiam registro institucional.

É essencial lembrar que incerteza e incapacidade de agir dominam muitos docentes, especialmente ao lidar diretamente com as vítimas, já que não existem no IFMA diretrizes oficiais habilitando-os para atuar e acompanhar as jovens. Além disso, essa equipe precisa superar suas dificuldades individuais para dar encaminhamento formal a casos reconhecidos, evitando expor a vítima e a si mesmo, evitando, também, represálias por parte do agressor.

\section{Procedimentos institucionais}

A escola brasileira tem tido dificuldades em incluir em sua pauta o enfrentamento de crises presentes no mundo atual ou em assumir o papel de agente transformador a partir da inserção no cotidiano sociocultural dos alunos. Faz-se importante abranger essas discussões no processo de ensino-aprendizagem, para que temas como diversidade cultural e de gênero aconteçam dentro da escola e não fora dela. Essa é uma forma de educar um cidadão capaz de viver e respeitar a pluralidade que constitui o contexto em que vive (DAVID et al, 2015).

Apesar de certos aspectos sobre violência ser parte do conteúdo dos cursos e estar em discussão conjunta com os discentes, não existe mediação do NAE para tal. Segundo os participantes, o maior entrave para assumir debates com esses vieses é o fato de não haver formação e incentivo dos gestores para que eles articulem assuntos transversais às disciplinas. Muitos professores sabem da importância desse enfoque, porém afirmam que a carga horária, a ementa e o quantitativo de alunos por sala de aula impossibilitam essa perspectiva. Assim, ministram o conteúdo formal e acreditam que estão cumprindo sua obrigação.

A complexidade desses temas demanda urgente mudanças nas grades curriculares, aproximando o conteúdo formal à realidade dos alunos. O estudo de Henrique e Nascimento (2015) mostra três principais obstáculos na aplicabilidade de pontos transversais nas disciplinas: não inserção de conteúdos e carga horária nos programas de ensino para desenvolvimento das 
práticas, superação da deficiência de qualificação do professor sobre essas abordagens e falta de recursos humanos especializados para a organização e desenvolvimento das atividades, dentro da classe.

Acrescenta-se aqui a dificuldade do IFMA em assumir um papel proeminente para tratar de assuntos polêmicos, como violências, casos de homofobia e etnicorracial. Alguns professores citam a necessidade de ir além da sala de aula no enfoque das violências, apontando que isso precisa ser trabalhado em conjunto entre os gêneros, porque, se as meninas vivenciam essas situações, os homens são responsáveis por tais atitudes:

Eu acredito que não adianta trabalhar a violência contra a mulher só com o público que sofre e que está em situação de vulnerabilidade. [...] temos que envolver o agente, o agressor, ele é o principal público-alvo para essa sensibilização, para essa mudança de comportamento. Eu acredito que os eventos tenham que envolver tanto os homens quanto as mulheres, até por conta do princípio da igualdade, eles têm que participar. Eu acredito que a violência tem que ser trabalhada de forma multidisciplinar, intersetorial e com os dois grupos juntos. (II)

Dois entrevistados concordam e acrescentam detalhes:

A gente pode trabalhar os dois juntos, sim, por exemplo, às vezes as meninas não se sentem muito à vontade para falar sobre determinados assuntos e [justamente] alguns assuntos devem ser tratados na presença dos meninos para que eles saibam que as meninas se sentem incomodadas com determinadas atitudes. [Só] aspectos específicos para quem já sofreu qualquer tipo de abuso ou de violência devem ser tratados de forma que não haja a exposição da aluna [...], por causa dos tabus que são feitos com relação a esse assunto, enrustido através da cultura do machismo. A gente precisa discutir, sim, é um assunto que a sociedade não pode mais fechar os olhos, até porque antigamente, por causa desse fechar de olhos, nós não tínhamos dados, hoje temos e eles estão alarmantes, a tal ponto de conseguirmos observar isso na rua, no condomínio, na família. (XVI)

Eu acho que poderíamos trabalhar em três momentos distintos. Um no geral explicando o que é. Aí fazer uma abordagem com as meninas e outra com os meninos, em separado. Com os meninos a gente poderia fazer uma abordagem na forma ética e legal sobre as consequências dos atos. Mas ser um momento multiprofissional, com psicólogo, pedagogo, saúde e os professores, porque eles, querendo ou não, são adolescentes e nos veem como uma referência para conversar, para desabafar. (III)

Além disso, outra função da escola é a de desenvolver os estudantes para construção de suas identidades para o mundo adulto, o que nem sempre se concretiza, pois é necessário desconstruir os padrões naturalizados e as RS existentes, como afirma a docente: "Não é porque ele é machista que ele está achando que é natural, é porque ele foi criado assim [...] e isso vai permanecer por muito tempo ainda" (XIII).

O conhecimento ministrado não traz elementos para enfrentar eventos dessa natureza, que deixam marcas subjetivas, reveladas por mudanças no comportamento, introspecção, dispersão em aula e desejo de isolamento. Isso não é observado, nem incluídos nos indicadores de desempenho no rendimento escolar. Para que a avaliação pedagógica abarque esses aspectos é necessário incorporar às disciplinas mais tradicionais uma visão crítica de hábitos culturais e formas de ser e viver, superando preconceitos, como afirma uma docente: “[...] educar, eu volto a dizer, não é só 
transmitir conhecimento, educar é uma formação geral. Você tem que se envolver com todos os problemas do aluno [...]" (XV).

Alguns docentes afirmam que a escola, frequentemente, fica inerte diante desses fatos e citam que há muito discurso e pouca prática, faltam normas claras e resolutivas, sobre como proceder o registro institucional para iniciar um processo no comitê de ética. Sem isso, a agressão continua e todos fingem que nada está acontecendo e não há notificação dos casos. Uma entrevistada relata sua vivência de passar a informação para a direção e não conseguir atender à necessidade da vítima com uma intervenção específica, levando o vitimador a se sentir livre para continuar com seu comportamento.

O sistema de enfrentamento desses atos precisa ser mais amplo e envolver a rede de assistência social, a saúde coletiva e a saúde mental, enfim, encaminhamentos para o Conselho Tutelar ou Ministério Público, conforme o caso. Enquanto isso não ocorre, professores não conseguem ultrapassar a agenda escolar pouco flexível, não se sentem preparados para entrar nessas polêmicas nem sugerir ações mais efetivas, pois falta-lhes habilitação para saber lidar com o contexto da vítima e do vitimador, de modo a não circunstanciar e empobrecer a análise.

\section{CONSIDERAÇÕES FINAIS}

Este estudo não tem a pretensão de fornecer todas as respostas à questão abordada, especialmente por se tratar de uma matéria intrincada vinculada dinamicamente entre saúde, saúde mental, educação, direitos humanos (racismo, gênero e etnia). O objetivo de conhecer essa realidade a partir da fala dos docentes é mostrar a dificuldade de evidenciar o assunto e o quanto as escolas, em geral, têm sido descuidadas no enfrentamento desses tipos de abusos, ao não instituir protocolos para registros, proteção e encaminhamentos de denúncias, causando, assim, subnotificação de ocorrências.

Dentre os vários tipos de violências, a forma silenciosa, presente nas narrativas analisadas, sobrepõe-se às demais e acaba negligenciada, naturalizada ou banalizada por quem a comete, por quem a assiste e, o mais espantoso, por quem a sofre. Assim, uma quantidade significativa de docentes do IFMA considera normais comportamentos machistas e que só deve intervir quando houver agressão física. Desse modo, as evidências sobre racismo são silenciadas e, portanto, têm maior dificuldade de serem esclarecidas. Isto porque racismo e machismo aparecem juntos com agravantes da violência silenciosa. "O racismo [...] é o ponto cego da violência de gênero e olhando a partir dele é possível evidenciar todos os pontos do sistema de dominação" (GEDELES, 2019) Essa maneira invisível não é captada de modo objetivo pelos profissionais, prejudicando o crescimento saudável dos alunos em suas diversas fases do desenvolvimento.

Docentes entrevistados demonstram seus preconceitos e juízos de valor diante das desigualdades sociais dentro e fora da escola, pressupondo que, na cultura nordestina, esse hábito na família é natural, o que evidencia a resistência dos elementos do núcleo das RS. Aqueles do gênero masculino relatam bloqueios pessoais, construídos ao longo de suas vivências, que os impedem de constatar as evidências físicas nas alunas, reconhecer e abordar essas vítimas. Justificam isso com a explicação que elas não sentem confiança em revelar suas questões e que algumas pedem para que a escola e os professores não se intrometam em suas vidas, pois, por diversas e desconhecidas razões, preferem ficar com o marido-pai-agressor. Outros argumentos encontrados nas respostas, especialmente de professoras, dizem respeito à dificuldade da direção do IFMA em prosseguir com isenção e sigilo à necessidade da vítima, para superação do evento, protegendo-as do medo de sofrer represálias por parte do agressor. 
Como aspecto positivo, após as entrevistas alguns docentes conseguiram ter outra compreensão de suas posições e ver a necessidade de descontruir suas próprias referências naturalizadas, RS, sobre machismo e violências, chegando a afirmar que passaram a ter vergonha de seus próprios preconceitos.

Minayo (2007, p.41) afirma que "[...] o contrário da violência não é a não-violência, mas sim a cidadania e a valorização da vida humana em geral e de cada indivíduo no contexto de seu grupo". Portanto, a meta básica do sistema escolar deve ser educar com qualidade na perspectiva de inclusão sujeito-aluno no ensino formal, a partir da visão integral do futuro cidadão, independente de gênero, cultura e etnia. Aliás, esses objetivos estão presente nos documentos oficiais do IFMA, mas não são seguidos.

Por fim, entende-se neste estudo que os casos vivenciados pelas alunas negras são um sintoma de uma realidade que só consegue ser revertida ao tornar visível a violência silenciosa, intersubjetiva e enraizada. Elucidar essa forma de violência — que passa incólume em situações de conflitos e sofrimentos físicos ou psíquicos — em um trabalho de educação em saúde é o caminho para superação dos efeitos causados entre equipes escolares e educandos, vítimas e vitimadores, numa uma relação cotidiana dual.

\section{REFERENNCIAS}

ALMEIDA, Neil Franco Pereira de et al. Formação docente e a temática étnico-racial. Revista Brasileira de Educação da ANPEd, Rio de Janeiro, v. 23, e230033, p. 1-24, jun., 2018.

BRAUN, Virginia; CLARK, Victoria. Successful Qualitative Research: A Practical Guide for Beginners. London: Sage, 2013.

COSTA, Andréia Lana; TEIXEIRA, Karla Maria Damiano. O comportamento dos alunos na escola e sua relação com a violência doméstica na percepção dos educadores. Oikos: Revista Brasileira de Economia Doméstica, Viçosa, v. 28. n. 1, p. 22-42, jun., 2017.

DAVID, Célia Maria et al. (orgs.). Desafios contemporâneos da educação. São Paulo: Editora UNESP; São Paulo: Cultura Acadêmica, 2015.

FÉRES-CARNEIRO, Terezinha (org.). Casal e família: transmissão, conflito e violência. São Paulo: Casa do Psicólogo, 2013.

GEDELES. Entre o machismo e o racismo. Instituto da Mulher Negra. 26 nov.2019. Disponível em https://www.geledes.org.br/entre-o-machismo-e-o-racismo. Acesso em 11 jun. 2021.

HENRIQUE, Ana Lúcia Sarmento; NASCIMENTO, José Mateus do. Sobre práticas integradoras: um estudo de ações pedagógicas na educação básica. HOLOS, Natal, v. 4, p. 63-76, ago., 2015.

INSTITUTO NACIONAL DE PESQUISA EDUCACIONAL ANÍSIO TEIXEIRA (INEP). Censo Escolar 2017. Brasília: INEP/MEC, 2017. Sinopse. Disponível em http://inep.gov.br/sinopses-estatisticas-da-educacao-basica. Acesso em 11 jun. 2019.

INSTITUTO DE PESQUISA ECONÔMICA APLICADA (IPEA) Marcondes, Mariana Mazzini et al. (orgs). Dossiê Mulheres Negras no Brasil. Brasilia: 2013. Disponível em https://www.ipea.gov.br/portal/images/stories/PDFs/livros/livros/livro dossie mulheres neg ras.pdf. Acesso em 11 jun. 2021

JESUS, Maria Lucia Gato de; MONTEIRO, Rosana Batista. Jovens, negras e estudantes: aspectos da vulnerabilidade em São Luís do Maranhão. Saúde soc., São Paulo, v. 25, n. 3, p. 652-663, set., 2016.

JODELET, Denise. As representações sociais. Rio de Janeiro: UERJ, 2001. 
MADUREIRA, Ana Flávia do Amaral; BRANCO, Ângela Uchoa. Gênero, sexualidade e diversidade na escola a partir da perspectiva de professores/as. Temas psicol., Ribeirão Preto, v. 23, n. 3, p. 577-591, set., 2015.

MELLO, Flávia Carvalho Malta et al. A prática de bullying entre escolares brasileiros e fatores associados, Pesquisa Nacional de Saúde do Escolar 2015. Ciênc. saúde coletiva, Rio de Janeiro, v. 22, n. 9, p. 2939-2948, set., 2017.

MENEGHEL, Stela Nazareth et al. Feminicídios: estudo em capitais e municípios brasileiros de grande porte populacional. Ciênc. saúde coletiva, Rio de Janeiro, v. 22, n. 9, p. 2963-2970, set., 2017.

MILES, Mathew B.; HUBERMAN, A. Michael. Qualitative Data Analysis: A Sourcebook of New Methods. 4. ed. New York: Sage, 2019.

MINAYO, Maria Cecília de Souza. Conceitos, teorias e tipologias de violência: a violência faz mal à saúde. In: NJAINE, K., ASSIS, S. G., e CONSTANTINO, P. Impactos da Violência na Saúde. Rio de Janeiro: Editora FIOCRUZ, 2007. p. 21-42.

MINAYO, Maria Cecília de Souza. Amostragem e saturação em pesquisa qualitativa: consensos e controvérsias. Revista Pesquisa Qualitativa, São Paulo, v. 5, n. 7, p. 01-12, abr., 2017.

MOSCOVICI, Serge. (1978). A Representação Social da Psicanálise. Rio de Janeiro: Zahar: 1978.

OLIVEIRA, Fernanda Piana Santos Lima de et al. Percepção de escolares do ensino fundamental sobre o Programa Saúde na Escola: um estudo de caso em Belo Horizonte, Brasil. Ciênc. saúde coletiva, Rio de Janeiro, v. 23, n. 9, p. 2891-2898, set., 2018.

RAZERA, Josiane; FALCKE, Denise. Relacionamento conjugal e violência: sair é mais difícil que ficar? Aletheia, Canoas, n. 45, p. 156-167, dez., 2014.

ORGANIZAÇÃO MUNDIAL DA SAÚDE (OMS). Relatório mundial sobre violência e saúde. Genebra: KRUG et al (Eds.), 2002.

SILVA, Luis Gustavo Moreira da; FERREIRA, Tarcisio José. O papel da escola e suas demandas sociais. Projeção e Docência, Brasilia, v. 5, n. 2, p. 6-23, dez., 2014.

SODRÉ, Muniz. Claros e escuros: identidade, povo, mídia e cotas no Brasil. 3. ed. Petrópolis: Vozes, 2015.

SOUZA, Jessé. A Ralé Brasileira. $3^{\text {a }}$ ed. São Paulo: Contracorrente. 2017.

Submetido em junbo de 2021

Aprovado em outubro de 2021

\section{Informações das autoras}

Ligia Costa Leite

Instituto de Psiquiatria, UFRJ, Universidade CEUMA, Maranhão.

E-mail: ligia.cleite@gmail.com

ORCID: https://orcid.org/0000-0003-3168-2799

Link Lattes: http://lattes.cnpq.br/6565933325978805

Rosse Imair de Oliveira Melo

Instituto Federal Educação, Ciência e Tecnologia do Maranhão (IFMA).

E-mail: rosseimair@yahoo.com.br

ORCID: https://orcid.org/0000-0001-8421-3684 
Link Lattes: http://lattes.cnpq.br/1789899409658502

Cristina Maria Douat

Universidade CEUMA, Maranhão. Instituto de Psiquiatria, UFRJ.

E-mail: crisloyola@hotmail.com

ORCID: https://orcid.org/0000-0003-2824-6531

Link Lattes: http://lattes.cnpq.br/5128815127967620 